\title{
Utjecaj vrste i udjela diizocijanata na toplinska i mehanička svojstva mješavina poliuretana i polikarbonata
}

\author{
E. Govorčin Bajsić* i A. Peršić \\ Sveučilište u Zagrebu Fakultet kemijskog inženjerstva i tehnologije, Marulićev trg 19, 10000 Zagreb
}

Ovo djelo je dano na korištenje pod Creative Commons Attribution 4.0

\begin{abstract}
Sažetak
U ovom radu istražen je utjecaj vrste i udjela diizocijanata u poliuretanskim elastomerima (PU) na njegovu mješljivost s polikarbonatom (PC) te je dobivena korelacija između sastava mješavina, vrste i udjela diizocijanata u PU-u, toplinskih i reoloških svojstva važnih za primjenu te mehaničkih svojstva. Mješavine PU/PC pripravljene su miješanjem elastomera PU na osnovi poliesterskog tipa poliola uz aromatski $(\mathrm{MDI})$ i cikloalifatski $\left(\mathrm{H}_{12} \mathrm{MDI}\right)$ diizocijanat, različitih udjela diizocijanata $(\mathrm{NCO} / \mathrm{OH}=2 / 1$ i 4/1) i PC-a u Brabender mikseru.

Rezultati mjerenja DSC-om pokazali su kristalnu strukturu PU-a na osnovi tipa diizocijanata MDI u odnosu na PU s $\mathrm{H}_{12} \mathrm{MDI}$ tipom diizocijanata, koji ima amorfnu strukturu. Rezultati mjerenja DMA-om ukazuju na djelomičnu mješljivost mješavina PU/ PC. Bolja mješljivost postignuta je kod mješavina PU/PC s tipom diizocijanata $\mathrm{H}_{12} \mathrm{MDI}$ i uz veći udjel tvrdog segmenta u odnosu na tip diizocijanata MDI.

Ključne riječi

Poliuretan (PU), polikarbonat (PC), mješavine, aromatski diizocijanat (MDI), cikloalifatski diizocijanat (H $\left.{ }_{12} \mathrm{MDI}\right)$
\end{abstract}

\section{Uvod}

Otkriće, razvoj i uporaba materijala oduvijek je bila vrlo bitan čimbenik razvoja ljudske civilizacije. Živimo u svijetu brzog razvoja tehnologije, gdje je konstantno prisutna potreba za poboljšanjem postojećih i stvaranjem novih materijala koji nalaze svoju primjenu u proizvodnji. Poliuretan je jedinstven materijal, koji nudi elastičnost gume u kombinaciji s čvrstoćom i trajnosti metala. ${ }^{1,2,3} \mathrm{U}$ odnosu na ostale polimere, poliuretani pokazuju veliku otpornost na udar i trošenje. Svoju primjenu nalaze u građevini i arhitekturi, strojarstvu, elektronici, tekstilnoj industriji, medicini, itd. Poliuretani (PU) su linearno segmentirani kopolimeri koji se sastoje od naizmjeničnih tvrdih (HS) i mekih segmenata (SS). ${ }^{4,5}$ Tvrdi segment sastoji se od diizocijanata i kratkih molekula produživača lanca, kao što su dioli ili diamini koji su kruti i visokopolarni. Zbog prisutnosti vodikovih veza u tvrdom segmentu dolazi do međumolekulnih interakcija između skupina uretan-urea. Vodikove veze unutar tvrdih segmenata u PU-u djeluju kao ojačanje za slabu matricu mekog segmenta. S druge strane, meki segmenti su dugolančani dioli ili polioli, koji su fleksibilni i slabo polarni. Molekule poliuretana izgrađene su od segmenata blok-kopolimera sastavljenih od relativno dugih i savitljivih polieterskih ili poliesterskih segmenata koji predstavljaju meke segmente, koji su kovalentno povezani sa segmentima uretanskih blokova i predstavljaju tvrde segmente. U PU-u dolazi do odvajanja faza zbog termodinamičke nemješljivosti između tvrdog i mekog segmenta. ${ }^{6,7}$ Termoplastični polikarbonat (PC) je amorfan polimer, koji se često upotrebljava kao polimerni materijal, zbog njegove izvanredne kombinacije uporabnih svojstava i niske cijene, kao i zbog njegove strukture koja se jednostavno modificira. Odlike

*Autor za dopisivanje: prof. dr. sc. Emi Govorčin Bajsić e-pošta: egovor@fkit.hr
PC-a su velika krutost, čvrstoća i žilavost te svoju primjenu nalazi u arhitekturi (staklo, zaštita od korozije, podovi), medicini (medicinska oprema, leće, zubne ispune), autoindustriji (auto-prevlake, dijelovi interijera), elektronici (CD, DVD, mobilna kućišta) i mnogim drugim područjima. Važno svojstvo na kojem se temelji primjena u medicini je biokompatibilnost, što znači da je PC osnovni, esencijalni element za dijelove koji su u izravnom i neizravnom kontaktu s pacijentom. Međutim primjena polikarbonata (PC) u mješavinama s drugim polimerima ograničena je zbog visoke temperature prerade $\mathrm{PC}-\mathrm{a}$, na kojima može doći do njihove toplinske razgradnje. ${ }^{8,9}$ Ti problemi mogu se djelomično riješiti miješanjem amorfnih i termoplastičnih materijala, kao što su polikarbonat i termoplastični poliuretan, pri čemu se dobivaju mješavine dobrih mehaničkih, toplinskih i reoloških svojstava. ${ }^{10,11}$

Cilj ovoga rada je istražiti utjecaj vrste elastomera PU na njegovu mješljivost s PC-om i dobiti korelaciju između sastava mješavina, vrste i udjela pojedinih faza u mješavinama te utjecaj vrste elastomera PU na morfološku strukturu, mehanička, toplinska i reološka svojstva važna za primjenu. $\mathrm{U}$ tu svrhu sintetizirani su elastomeri PU s masenim udjelom tvrdog segmenta od 35 i $52 \%$ uz aromatski (MDI) i cikloalifatski $\left(\mathrm{H}_{12} \mathrm{MDI}\right)$ diizocijanat.

\section{Eksperimentalni dio}

\subsection{Materijali}

Priređene su četiri serije elastomera PU na osnovi poliesterskog tipa poliola uz aromatski (MDI) i cikloalifatski $\left(\mathrm{H}_{12} \mathrm{MDI}\right)$ diizocijanat te različite udjele tvrdog segmenta, odnosno različite odnose skupina $\mathrm{NCO} / \mathrm{OH}$ u pretpolimeru $(2 / 1$ i $4 / 1)$. 
Tablica 1 - Sastav poliuretana korištenih u radu

Table 1 - Composition of polyurethane used in the work

\begin{tabular}{|c|c|c|c|c|c|}
\hline $\begin{array}{l}\text { Elastomer PU } \\
\text { Elastomer PU }\end{array}$ & $\begin{array}{l}\text { Poliol (proizvođač) } \\
\text { [trgovački naziv] } \\
\text { Polyol (manufacturer) } \\
\text { [trade name] }\end{array}$ & $\begin{array}{l}\text { Diizocijanat (proizvođač) } \\
\text { [trgovački naziv] } \\
\text { Diisocyanate } \\
\text { (manufacturer) } \\
\text { [trade name] }\end{array}$ & $\begin{array}{c}\text { Molekulska } \\
\text { masa poliola } \\
\text { Molecular mass } \\
\text { of polyols }\end{array}$ & $\begin{array}{l}\text { Maseni udjel } \\
\text { tvrdog segmenta u } \\
\text { pretpolimeru /\% } \\
\text { Mass fraction of the } \\
\text { hard segment in the } \\
\text { pre-polymer }\end{array}$ & $\begin{array}{c}\text { Omjer skupina } \mathrm{NCO} / \\
\mathrm{OH} \text { u pretpolimeru } \\
\mathrm{NCO} / \mathrm{OH} \text { ratio of the } \\
\text { pre-polymer }\end{array}$ \\
\hline PUES/MDI II & $\begin{array}{l}\text { PCL } \\
\text { (Union Carbide Corp.) }\end{array}$ & $\begin{array}{l}\text { MDI } \\
\text { (Miles) }\end{array}$ & & 34 & $2 / 1$ \\
\hline PUES/MDI IV & [Tone 0230] & [Unilink 4200] & 1250 & 51 & $4 / 1$ \\
\hline $\mathrm{PUES} / \mathrm{H}_{12} \mathrm{MDI}$ II & $\begin{array}{l}\text { PCL } \\
\text { (Union Carbide Corp.) }\end{array}$ & $\begin{array}{l}\mathrm{H}_{12} \mathrm{MDI} \\
\text { (Miles) }\end{array}$ & & 35 & $2 / 1$ \\
\hline PUES/H ${ }_{12}$ MDI IV & [Tone 0230] & [Desmodur W] & 1250 & 53 & $4 / 1$ \\
\hline
\end{tabular}

Upotrijebljene osnovne komponente za pripremu elastomera i njihov omjer izražen kroz omjer skupina $\mathrm{NCO} / \mathrm{OH}$ u pretpolimeru te udjel tvrdog segmenta prikazani su u tablici 1 .

\subsection{Priprava uzorka}

\subsubsection{Priprava uzoraka elastomera PU}

Poliuretanski (PU) elastomeri priređeni su pretpolimernim postupkom koji se odvija u dva stupnja (slika 1). Prvi stupanj odnosi se na pripravu pretpolimera polimerizacijom u masi diizocijanata s poliolom. Primijenjen je omjer $\mathrm{NCO} / \mathrm{OH} 2 / 1$ i 4/1. Diizocijanat je otopljen u reaktoru na temperaturi od $\approx 80{ }^{\circ} \mathrm{C}$ u struji dušika uz snažno mije- šanje. Nakon toga je diizocijanat ohlađen na $60{ }^{\circ} \mathrm{C}$ i uz miješanje mu je dodan poliol, bez uporabe katalizatora. Kraj reakcije određen je kad je razlika eksperimentalne vrijednosti NCO u odnosu na izračunatu vrijednost NCO $\approx 1 \%$. Koncentracija NCO u izocijanatu i pretpolimeru mjerena je metodom titracije uz dibutilamin, ASTM D 2572-80.

U drugom stupnju sintetizirani su elastomeri PU reakcijom pretpolimera i produživača lanca. U tu svrhu pretpolimer je zagrijan na $90{ }^{\circ} \mathrm{C}$ i uz snažno miješanje mu je dodan produživač lanca butan-1,4-diol. Reakcijska smjesa se zatim prešala u kalupu na temperaturi od $100{ }^{\circ} \mathrm{C}$ u vremenu od 30 min. Nakon vađenja iz kalupa elastomeri su 24 sata držani na temperaturi od $105{ }^{\circ} \mathrm{C}$, radi potpunog završetka reakcije, naknadnog umreženja.

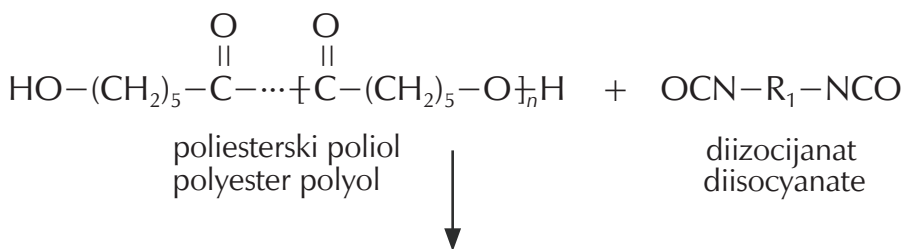<smiles>O=CN[R]NC(=O)OC(=O)CCCC(=O)C(=O)CCOC(=O)NC(=O)[O-]</smiles>

pretpolimer prepolymer

$$
\downarrow \begin{aligned}
& +\mathrm{HO}-\mathrm{R}_{2}-\mathrm{OH} \\
& \text { niskomolekulni diol } \\
& \text { low molecular weight diol }
\end{aligned}
$$

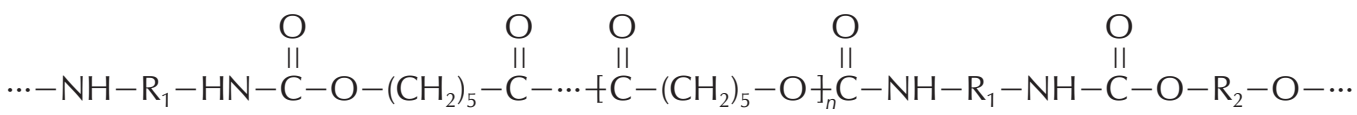

PU ES

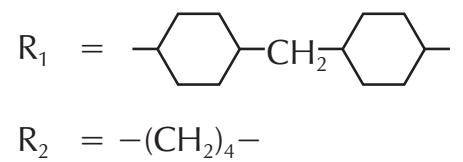

Slika 1 - Priprava elastomera PU pretpolimernim postupkom

Fig. 1 - Preparation of PU elastomer by prepolymer procedure 


\subsubsection{Priprava mješavina PU/PC}

Mješavine PU/PC, kao i čiste komponente priređene su u laboratorijskom mikseru Brabender, uz brzinu miješanja od 60 min $^{-1}, \mathrm{PC}$ je miješan na $190{ }^{\circ} \mathrm{C}$, PU na $180{ }^{\circ} \mathrm{C}$, a mješavine PU/PC na $190{ }^{\circ} \mathrm{C}$. Ispitna tijela dobivena su prešanjem granula u kalupu pri temperaturi od $220{ }^{\circ} \mathrm{C}$ na preši Dake Model 44-226.

\subsection{Karakterizacija}

\subsubsection{Diferencijalna pretražna kalorimetrija (DSC)}

Istraživanja su provedena na instrumentu Mettler Toledo DSC $822^{\mathrm{e}}$. Brzina zagrijavanja i hlađenja bila je $10{ }^{\circ} \mathrm{C} \mathrm{min}^{-1}$. Mjerenja su provedena u području temperature od $-100{ }^{\circ} \mathrm{C}$ do $250{ }^{\circ} \mathrm{C}$, uz težinu uzorka do $10 \mathrm{mg}$. Proveden je dvostruki ciklus zagrijavanja i hlađenja i karakteristične vrijednosti određene su iz drugog ciklusa. Hlađenje na niske temperature postignuto je tekućim dušikom.

\subsubsection{Dinamičko mehanička analiza (DMA)}

Dinamičko mehanički analizator DMA 983, proizvođač TA instruments, upotrijebljen je za mjerenje primarnih viskoelastičnih funkcija, modula gubitka $E^{\prime \prime}$ i modula pohrane $E^{\prime}$. Mjerenja su provedena pri konstantnoj frekvenciji od $1 \mathrm{~Hz}$, pri amplitudi od $0,35 \mathrm{~mm}$ i uz brzinu zagrijavanja od $3{ }^{\circ} \mathrm{C} \mathrm{min}^{-1}$. Temperaturno područje mjerenja bilo je od $-100{ }^{\circ} \mathrm{C}$ do $200{ }^{\circ} \mathrm{C}$. Dimenzije uzorka bile su $20,00 \times 13,00 \times 1,00 \mathrm{~mm}$. Tekući dušik upotrijebljen je za hlađenje na niske temperature.

\subsubsection{Mehanička svojstva}

Mehanička svojstva određena su na univerzalnom uređaju za mehanička ispitivanja Zwick 1445 na sobnoj temperaturi i uz brzinu ispitivanja od $10,0 \mathrm{~mm} \mathrm{~min}^{-1}$. Ispitano je pet ispitnih tijela za svaki uzorak izmjera $80,0 \mathrm{~mm} \times 15,0 \mathrm{~mm} \times 1,0 \mathrm{~mm}$.

\section{Rezultati i rasprava}

\subsection{Mješavine PU i PC na osnovi aromatskog diizocijanata}

\subsubsection{Karakterizacija mješavina PU/PC DSC tehnikom}

Na slici 2 prikazane su DSC krivulje čistog elastomera PU na osnovi aromatskog diizocijanata i esterskog tipa poliola uz različite udjele diizocijanata $(\mathrm{NCO} / \mathrm{OH} 2 / 1$ i 4/1). $\mathrm{Na}$ DSC krivulji elastomera PU s manjim udjelom diizocijanata (PU ES MDI 2/1) vidljiva je pojava staklišta $\left(T_{\mathrm{g}}\right)$ na $-27,1^{\circ} \mathrm{C}$, a na višim temperaturama vidljiva je pojava širokog endotermnog prijelaza na $119,6{ }^{\circ} \mathrm{C}$ koji odgovara talištu tvrdog segmenta. ${ }^{2,13}$

Stupanj kristalnosti elastomera PU $\left(\chi_{c}\right)$ izračunat je na osnovi vrijednosti $\Delta H_{\mathrm{m}}$ dobivenih iz mjerenja DSC preko izraza (1):

$$
\chi_{\mathrm{c}}=\Delta H_{\mathrm{m}}^{\circ} / \Delta H_{\mathrm{m}}{ }^{100}
$$

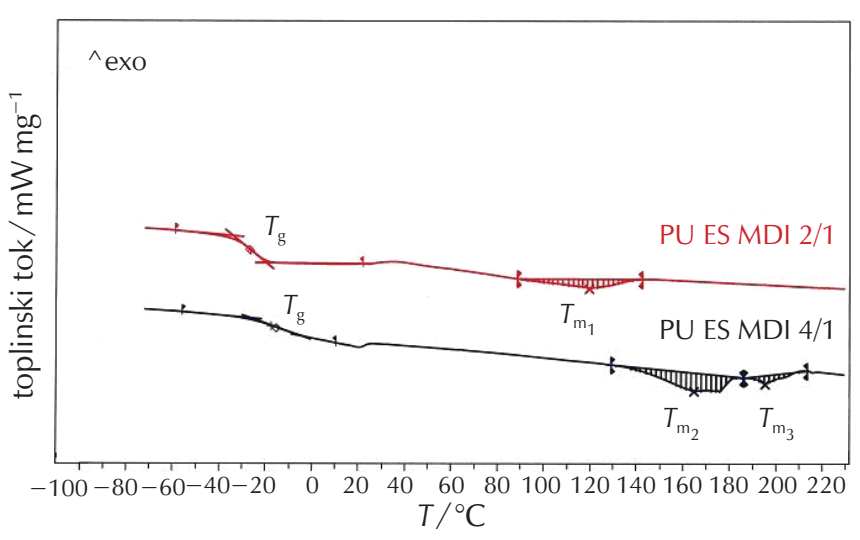

Slika 2 - Krivulje DSC elastomera PU na osnovi aromatskog diizocijanata uz omjer NCO/OH 2/1 i 4/1

Fig. 2 - DSC curves of PU elastomers based on aromatic diisocyanate with $\mathrm{NCO} / \mathrm{OH}$ content of $2 / 1$ i $4 / 1$

gdje $\Delta H_{\mathrm{m}}{ }^{\circ}\left(\mathrm{J} \mathrm{g}^{-1}\right)$ predstavlja vrijednosti dobivene mjerenjem DSC, a $\Delta H_{\mathrm{m}}{ }^{100}\left(\mathrm{~J} \mathrm{~g}^{-1}\right)$ odgovara $100 \%$ kristalastom PU-u i iznosi 24,393 J g ${ }^{-1} .{ }^{14}$ Stupanj kristalnosti elastomera PU iznosi 18,03 \%, povećanjem udjela diizocijanata kristalnost se povećava (tablica 2). Povećanjem udjela tvrdog segmenta staklište $\left(T_{\mathrm{g}}\right)$ pomiče se na višu temperaturu kao posljedica smanjene pokretljivosti mekog segmenta u elastomeru PU.

Krivulje DSC mješavina PU/PC s manjim udjelom diizocijanata (NCO/OH 2/1) prikazane su na slici 3. Vidljiva je pojava $T_{\mathrm{g}}$ na nižim temperaturama vezanog za meku poliestersku fazu PU. Kod masenih udjela PC-a od 30 i $50 \%$ dobiveno je talište $\left(T_{\mathrm{m}}\right)$ tvrde poliuretanske faze koje se preklapa s $T_{\mathrm{g}} \mathrm{PC}-\mathrm{a}$, dok se kod masenog udjela od $70 \%$ PC-a javlja $T_{\mathrm{g}}$ PC-a koje je pomaknuto na niže temperature u odnosu na čisti PC $\left(140,1^{\circ} \mathrm{C}\right)$. U prve dvije mješavine (PU/PC 70/30 i PU/PC 50/50) PC je dobro dispergiran u poliuretanskoj matrici, na višim temperaturama dobiveni su endotermi vezani za talište $\left(T_{\mathrm{m}}\right)$ tvrde faze PU-a. Amorfna struktura PC-a utječe na razrušavanje kristalne strukture tvrde faze $\mathrm{PU}-\mathrm{a}, T_{\mathrm{m}}$ je pomaknu-

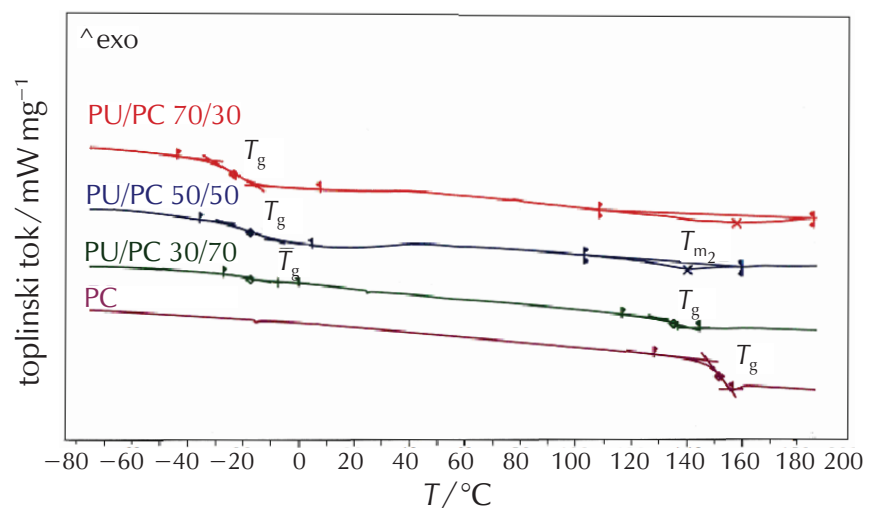

Slika 3 - Krivulje DSC mješavina PU/PC na osnovi aromatskog diizocijanata (MDI) uz udjel NCO/OH 2/1

Fig. 3 - DSC curves of PU/PC blends based on aromatic diisocyanate (MDI) with $\mathrm{NCO} / \mathrm{OH} 2 / 1$ 
Tablica 2 - Prikaz rezultata dobivenih mjerenjem DSC

Table 2 - Results obtained by DSC measurements

\begin{tabular}{|c|c|c|c|c|c|}
\hline $\begin{array}{l}\text { Uzorak } \\
\text { Sample }\end{array}$ & $T_{\mathrm{g}(\mathrm{PC})} /{ }^{\circ} \mathrm{C}$ & $T_{\mathrm{g}(\mathrm{PU})} /{ }^{\circ} \mathrm{C}$ & $T_{\mathrm{m} 1,2,3} /{ }^{\circ} \mathrm{C}$ & $\Delta H^{\circ}{ }_{\mathrm{m}} / \mathrm{Jg}^{-1}$ & $\chi_{\mathrm{c}} / \%$ \\
\hline PUES MDI 2/1 & - & $-27,0$ & $\begin{array}{c}119,4 \\
- \\
-\end{array}$ & 4,40 & 18,03 \\
\hline PUES MDI 4/1 & - & $-15,8$ & $\begin{array}{c}164,4 \\
- \\
194,7\end{array}$ & 10,32 & 42,29 \\
\hline PC 100 & 140,1 & - & - & - & - \\
\hline $\begin{array}{l}\text { PUES MDI 2/1; } \\
\text { PU/PC 70/30 } \\
\text { PU/PC 50/50 } \\
\text { PU/PC 30/70 }\end{array}$ & $\begin{array}{c}- \\
- \\
135,5\end{array}$ & $\begin{array}{l}-23,2 \\
-17,3 \\
-17,1\end{array}$ & $\begin{array}{c}- \\
158,0 \\
140,2 \\
-\end{array}$ & $\begin{array}{c}3,48 \\
1,67 \\
-\end{array}$ & $\begin{array}{c}14,27 \\
6,85 \\
-\end{array}$ \\
\hline $\begin{array}{l}\text { PUES MDI 4/1; } \\
\text { PU/PC } 70 / 30 \\
\text { PU/PC 50/50 } \\
\text { PU/PC 30/70 }\end{array}$ & $\begin{array}{l}130,1 \\
132,0 \\
131,5\end{array}$ & $\begin{array}{l}-16,3 \\
-22,1 \\
-22,6\end{array}$ & $\begin{array}{l}- \\
- \\
-\end{array}$ & $\begin{array}{l}- \\
- \\
-\end{array}$ & $\begin{array}{l}- \\
- \\
-\end{array}$ \\
\hline
\end{tabular}

ta na nižu temperaturu i smanjen je stupanj kristalnosti tvrde faze (tablica 2). Staklište meke faze PU-a dodatkom PC-a $(w(P C)=70 \%)$ pomiče se na više temperature, a PC-a na niže, što ukazuju na djelomičnu mješljivost PU-a i PC-a kod ovog omjera PU/PC.

Na slici 4 prikazane su krivulje DSC mješavina PU/PC s većim udjelom diizocijanata $(\mathrm{NCO} / \mathrm{OH} 4 / 1)$. Povećanjem udjela diizocijanata postignuta je mješljivost kod masenog udjela PC-a od 30 mas \%, $T_{\mathrm{g}}$ meke amorfne faze PU-a i PC-a pomaknuto je na višu temperaturu uslijed smanjenja pokretljivosti lanaca mekog segmenta dodatkom većeg udjela kristalnog diizocijanata. Kod masenih udjela PC-a od 50 i 70 mas \%, $T_{\mathrm{g}}$ je pomaknuto na niže temperature, što ukazuje na mješljivost amorfne meke faze PU-a i amorfne faze PC-a koja utječe na povećanje pokretljivosti amorfne faze.

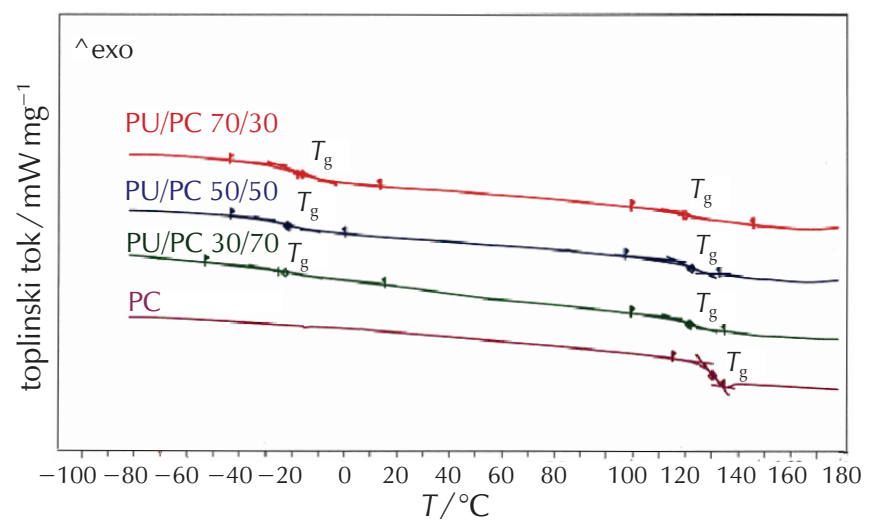

Slika 4 - Krivulje DSC mješavina PU/PC na osnovi aromatskog diizocijanata (MDI) uz udjel $\mathrm{NCO} / \mathrm{OH} 4 / 1$

Fig. 4 - DSC curves of PU/PC blends based on aromatic diisocyanate (MDI) with $\mathrm{NCO} / \mathrm{OH} 4 / 1$

\subsubsection{Analiza DMA mješavina PU/PC}

Na slikama 5 a) i 5 b) prikazane su krivulje modula gubitka o temperaturi za mješavine PU/PC s manjim udjelom diizocijanata $(\mathrm{NCO} / \mathrm{OH}=2 / 1)$ odnosno s većim udjelom diizocijanata $(\mathrm{NCO} / \mathrm{OH}=4 / 1)$.
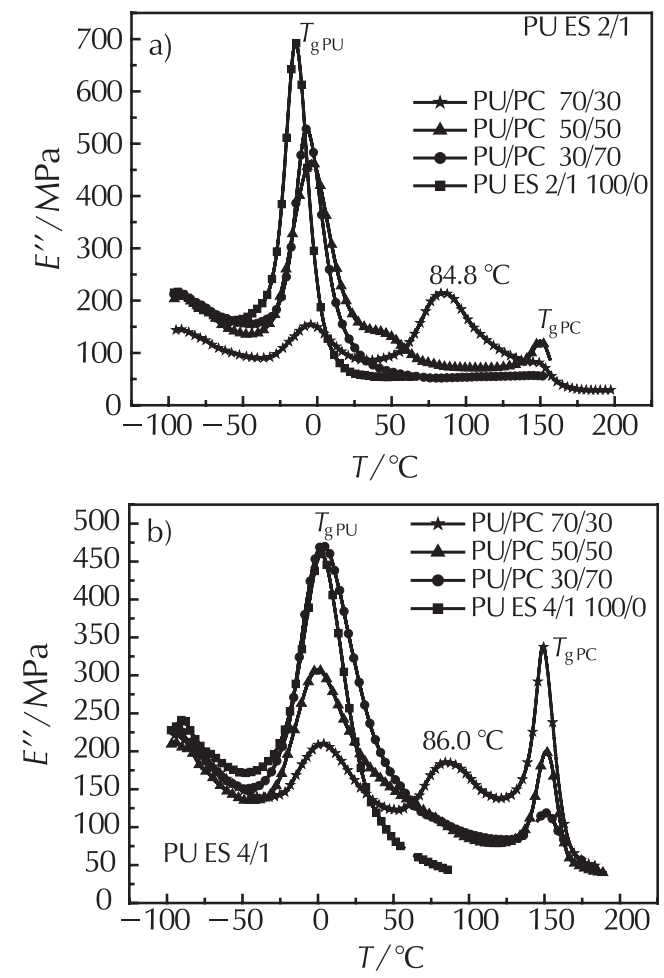

Slika 5 - Modul gubitka $\left(E^{\prime \prime}\right)$ u ovisnosti o temperaturi za mješavine PU/PC uz a) NCO/OH 2/1 i b) NCO/OH 4/1

Fig. 5 - Loss modulus $\left(E^{\prime \prime}\right)$ for PU/PC blends with a) $\mathrm{NCO} / \mathrm{OH}$ $2 / 1$, and b) $\mathrm{NCO} / \mathrm{OH} 4 / 1$ as a function of temperature 
Na svim krivuljama mješavina PU/PC javljaju se dva relaksacijska maksimuma vezana za $T_{\mathrm{g}} \mathrm{PU}$-a na nižim temperaturama, ${ }^{15}$ odnosno $T_{\mathrm{g}}$ PC-a na višim temperaturama. ${ }^{16}$ Relaksacijski maksimum koji predstavlja $T_{\mathrm{g}}$ amorfne poliesterske faze PU-a dodatkom PC-a pomiče se na više temperature, proširuje se i smanjuje mu se intenzivnost, što ukazuje na djelomičnu mješljivost PU-a i PC-a (isti rezultat dobiven je i mjerenjem DSC). Ahn i ostali autori u svojim su istraživanjima mješljivosti TPU-a na osnovi poliesterskog tipa poliola i PC-a dokazali da je TPU na osnovi poliester poliola mješljiv s PC-om, dok tvrdi segment nije mješljiv s PC-om. ${ }^{16}$ Povećanjem udjela tvrdog segmenta maksimumi se više proširuju, snižava im se intenzivnost i pomiču se na više temperature kao posljedica povećanja mješljivosti PU-a i PC-a.

Kod mješavina s masenim udjelom PC-a od 70 mas \% uočava se pojava novog relaksacijskog maksimuma na oko $80{ }^{\circ} \mathrm{C}$. Taj relaksacijski maksimum vezan je za nastajanje kopolimera PU-PC reakcijom hidroksidne skupine iz PC-a i uretanske skupine iz PU-a, kao što je pokazano na slici 6.

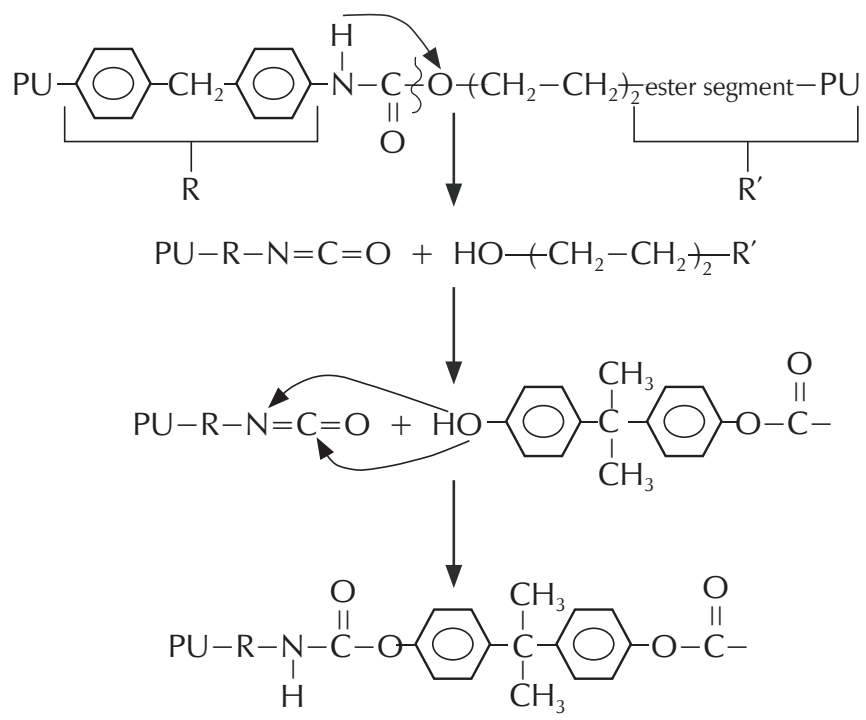

Slika 6 - Reakcija nastajanja PU/PC kopolimera

Fig. 6 - Reaction of PU/PC copolymer formation
Taj kopolimer djeluje kao kompatibilizator tako da poboljšava kompatibilnost PU-a i PC-a.

Na slikama 7 a) i 7 b) prikazana je ovisnost modula pohrane $\left(E^{\prime}\right)$ o temperaturi za sve mješavine PU/PC s manjim i većim udjelom diizocijanata.
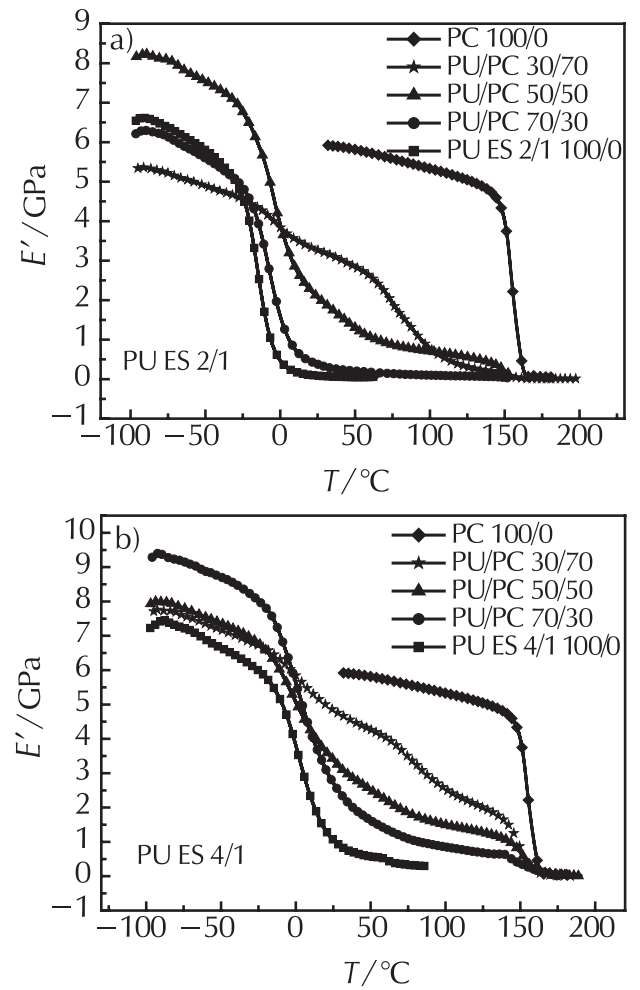

Slika 7 - Modul pohrane $\left(E^{\prime}\right)$ u ovisnosti o temperaturi za mješavine $\mathrm{PU} / \mathrm{PC}$ uz a) $\mathrm{NCO} / \mathrm{OH} 2 / 1$ i b) NCO/OH 4/1

Fig. 7 - Storage modulus ( $\left.E^{\prime}\right)$ for $\mathrm{PU} / \mathrm{PC}$ blends with a) $\mathrm{NCO} / \mathrm{OH}$ $2 / 1$, and b) $\mathrm{NCO} / \mathrm{OH} 4 / 1$ as a function of temperature

Povećanjem udjela PC-a kao i udjela diizocijanata, krivulje modula pohrane pomiču se prema višim temperaturama u odnosu na čiste polimere i nalaze se između krivulja čistog

Tablica 3 - Prikaz rezultata dobivenih mjerenjem DMA

Table 3 - Results obtained by DMA measurements

\begin{tabular}{|c|c|c|c|c|c|}
\hline $\begin{array}{l}\text { Uzorak } \\
\text { Sample }\end{array}$ & $T_{\mathrm{g}(\mathrm{PC})} /{ }^{\circ} \mathrm{C}$ & $T_{\mathrm{g}(\mathrm{PU})} /{ }^{\circ} \mathrm{C}$ & $I_{\mathrm{E}^{\prime \prime} \mathrm{PC}} / \mathrm{MPa}$ & $I_{\mathrm{E}^{\prime \prime P U}} / \mathrm{MPa}$ & $E^{\prime}{ }_{25^{\circ} \mathrm{C}} / \mathrm{GPa}$ \\
\hline $\begin{array}{l}\text { PU ES MDI 2/1 } \\
\text { PU ES MDI } 4 / 1\end{array}$ & & $\begin{array}{r}-14,6 \\
2,2\end{array}$ & & $\begin{array}{l}693,1 \\
459,8\end{array}$ & $\begin{array}{l}0,090 \\
1,050\end{array}$ \\
\hline PC 100 & 154,4 & & 1001 & & 5,921 \\
\hline $\begin{array}{l}\text { PU ES MDI 2/1 : } \\
\text { PU/PC 70/30 } \\
\text { PU/PC 50/50 } \\
\text { PU/PC 30/70 }\end{array}$ & $\begin{array}{l}147,5 \\
150,1 \\
148,3\end{array}$ & $\begin{array}{l}-7,1 \\
-4,0 \\
-4,2\end{array}$ & $\begin{array}{r}56,7 \\
121,9 \\
154,4\end{array}$ & $\begin{array}{l}527,3 \\
465,8 \\
214,4\end{array}$ & $\begin{array}{l}0,374 \\
2,067 \\
3,260\end{array}$ \\
\hline $\begin{array}{l}\text { PU ES MDI 4/1 : } \\
\text { PU/PC 70/30 } \\
\text { PU/PC 50/50 } \\
\text { PU/PC 30/70 }\end{array}$ & $\begin{array}{l}151,4 \\
151,2 \\
149,1\end{array}$ & $\begin{array}{l}3,4 \\
0,0 \\
3,1\end{array}$ & $\begin{array}{l}118,7 \\
198,4 \\
209,5\end{array}$ & $\begin{array}{l}471,0 \\
307,3 \\
333,1\end{array}$ & $\begin{array}{l}2,731 \\
3,398 \\
4,833\end{array}$ \\
\hline
\end{tabular}


PU-a i PC-a, što ukazuje na djelomičnu mješljivost PU-a i PC-a te povećanje krutosti dodatkom PC-a i većeg udjela diizocijanata.

\subsubsection{Mehanička svojstva}

Rezultati mjerenja mehaničkih svojstavaza mješavinePU/PC s različitim udjelom PC-a i diizocijanata prikazani su na slici 8 i u tablici 4 . Iz rezultata je vidljivo da dolazi do porasta prekidne čvrstoće i pada prekidnog istezanja povećanjem udjela diizocijanata i PC-a. Taj rezultat može se pripisati
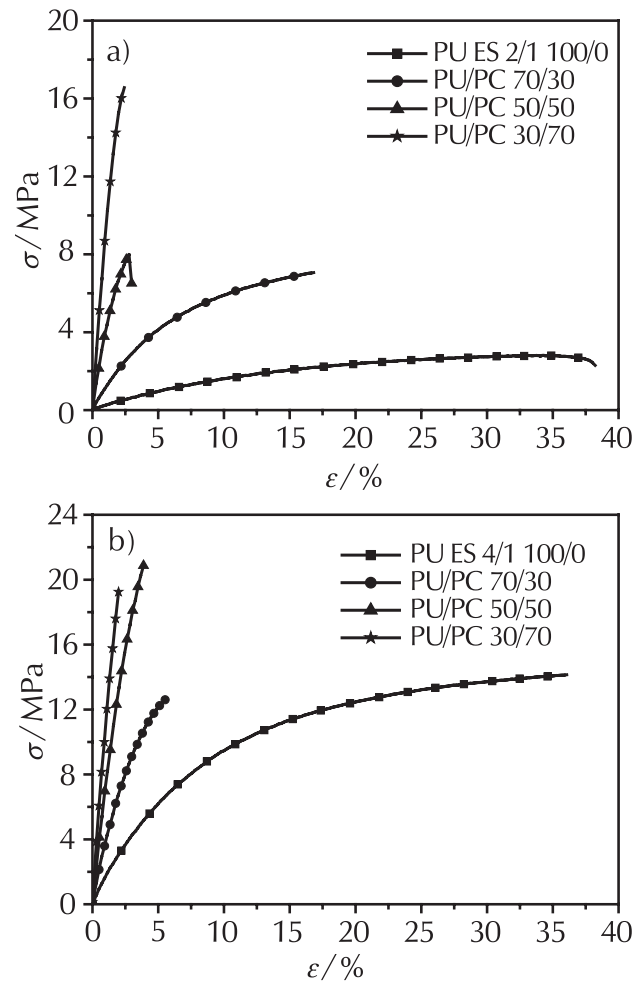

Slika 8 - Usporedne krivulje naprezanja-istezanja za mješavine $\mathrm{PU} / \mathrm{PC}$ uz a) $\mathrm{NCO} / \mathrm{OH} 2 / 1$ i b) $\mathrm{NCO} / \mathrm{OH} 4 / 1$

Fig. 8 - Stress-strain curves for PU/PC blends with a) $\mathrm{NCO} / \mathrm{OH}$ $2 / 1$, and b) $\mathrm{NCO} / \mathrm{OH} 4 / 1$

Tablica 4 - Prikaz rezultata mehaničkih svojstava Table 4 - Results of mechanical properties

\begin{tabular}{l|r|r|r}
\hline $\begin{array}{l}\text { Uzorak } \\
\text { Sample }\end{array}$ & $\sigma / \mathrm{N} \mathrm{mm}^{-2}$ & $\varepsilon / \%$ & $E / \mathrm{MPa}$ \\
\hline PU ES MDI 2/1 & 9,12 & 99,28 & 105,50 \\
PU ES MDI 4/1 & 11,01 & 13,92 & 316,50 \\
PC 100 & 28,3 & 2,00 & 1716,80 \\
PU ES MDI 2/1 : & & & \\
PU/PC 70/30 & 8,37 & 58,68 & 136,08 \\
PU/PC 50/50 & 11,20 & 12,12 & 321,00 \\
PU/PC 30/70 & 16,56 & 2,42 & 809,00 \\
PU ES MDI 4/1 : & & & \\
PU/PC 70/30 & 12,99 & 10,52 & 316,50 \\
PU/PC 50/50 & 13,83 & 3,20 & 818,80 \\
PU/PC 30/70 & 16,29 & 3,20 & 1089,30 \\
\hline
\end{tabular}

povećanju krutosti mješavina dodatkom većeg udjela tvrde faze PU-a i PC-a koji ima znatno veću čvrstoću u odnosu na PU (tablica 4).

\subsection{Mješavine PU/PC na osnovi cikloalifatskog diizocijanata}

\subsubsection{Karakterizacija mješavina PU/PC DSC tehnikom}

Krivulje elastomera PU na osnovi poliester poliola i cikloalifatskog diizocijanata $\left(\mathrm{H}_{12} \mathrm{MDI}\right)$ dobivene DSC tehnikom prikazane su na slici 9. Na krivuljama elastomera PU uz oba udjela diizocijanata (PU ES W 2/1 i PU ES W 4/1) vidljivo je samo staklište $\left(T_{\mathrm{g}}\right)$ meke poliesterske faze što ukazuje na amorfnu strukturu u odnosu na elastomere PU na osnovi aromatskog izocijanata koji imaju semikristalnu strukturu.

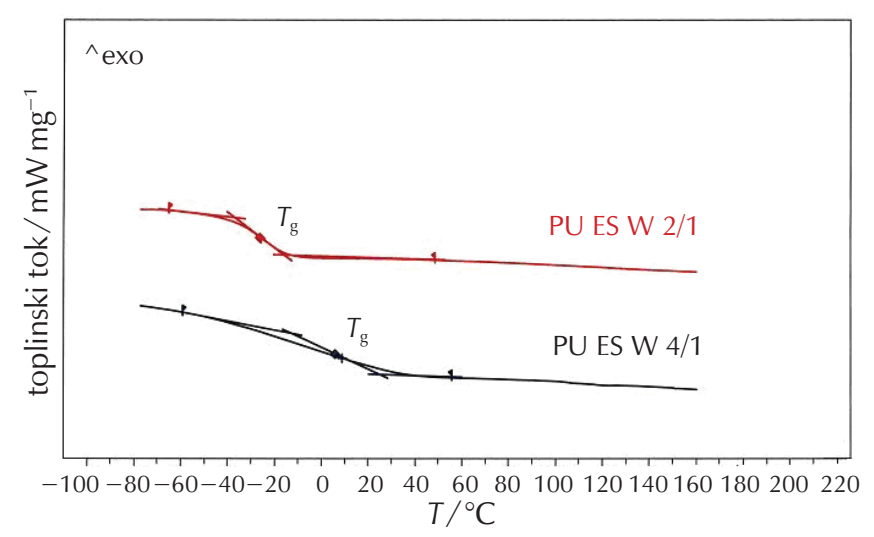

Slika 9 - Krivulje DSC elastomera PU na osnovi cikloalifatskog diizocijanata uz omjer NCO/OH 2/1 i 4/1

Fig. 9 - DSC curves of PU elastomers based on cycloaliphatic diisocyanate with $\mathrm{NCO} / \mathrm{OH} 2 / 1$ and 4/1

Na slici 10 prikazane su krivulje DSC mješavina PU/PC s manjim udjelom diizocijanata (PUES W 2/1). Vidljiv je po-

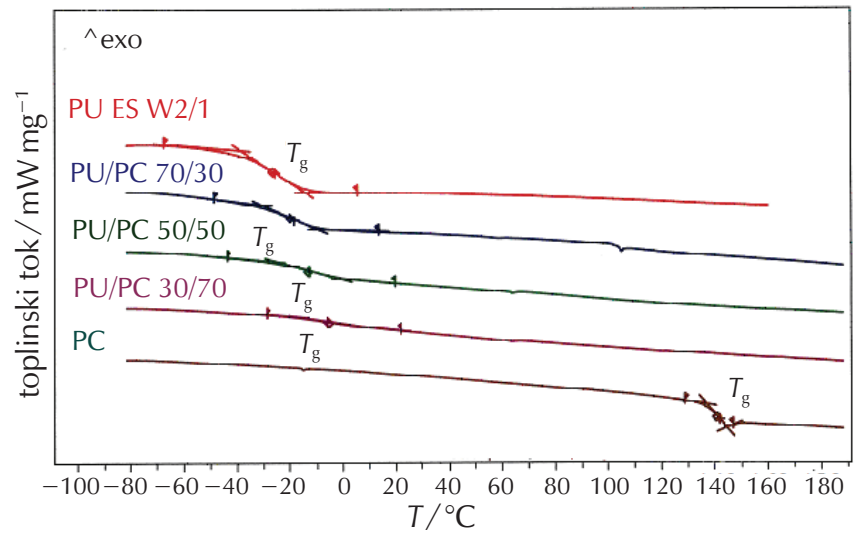

Slika 10 - Krivulje DSC mješavina PU/PC na osnovi cikloalifatskog diizocijanata $\left(\mathrm{H}_{12} \mathrm{MDI}\right)$ uz udjel $\mathrm{NCO} / \mathrm{OH} 2 / 1$

Fig. 10 - DSC curves of PU/PC blends based on cycloaliphatic diisocyanate $\left(\mathrm{H}_{12} \mathrm{MDI}\right)$ with $\mathrm{NCO} / \mathrm{OH} 2 / 1$ 
mak $T_{\mathrm{g}}$ poliesterske faze $\mathrm{PU}$-a na više temperature dodatkom amorfnog PC-a, što ukazuje na djelomičnu mješljivost PU-a i PC-a. Staklište PC-a nije dobiveno, te se može pretpostaviti da je PC dispergiran u amorfnoj matrici esterske meke faze i uretanske tvrde faze.

Povećanjem udjela diizocijanata $T_{\mathrm{g}}$ meke faze $\mathrm{PU}$-a pomaknuto je na znatno višu temperaturu u odnosu na PU $\mathrm{s}$ manjim udjelom tvrdog segmenta (razlika u temperaturi je oko $30{ }^{\circ} \mathrm{C}$, tablica 5 , slika 11 . Na krivuljama je dobiveno $T_{\mathrm{g}}$ PC-a koje je pomaknuto na nižu temperaturu u odnosu na čisti PC, što nam također ukazuje na mješljivost PU-a i PC-a.

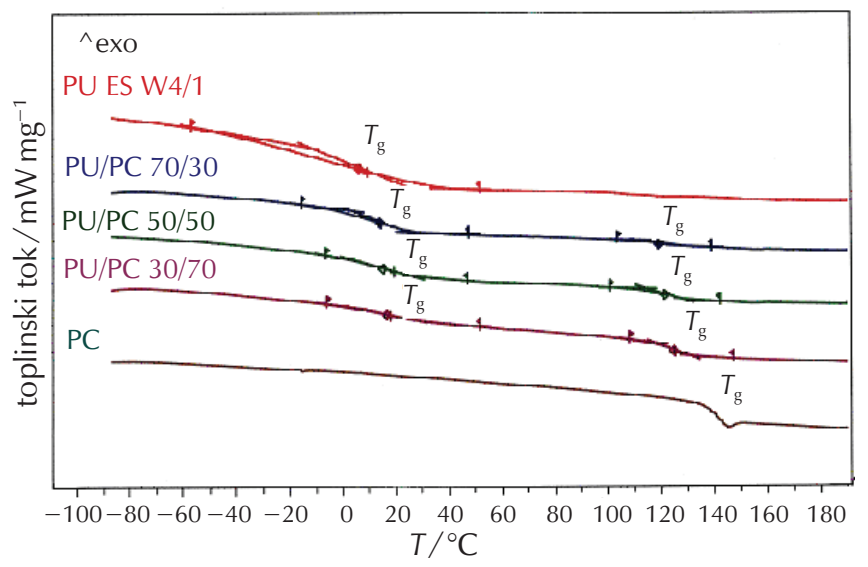

Slika 11 - Krivulje DSC mješavina PU/PC na osnovi cikloalifatskog diizocijanata $\left(\mathrm{H}_{12} \mathrm{MDI}\right)$ uz udjel $\mathrm{NCO} / \mathrm{OH} 4 / 1$

Fig. 11 - DSC curves of PU / PC blends based on cycloaliphatic diisocyanate $\left(\mathrm{H}_{12} \mathrm{MDI}\right)$ with $\mathrm{NCO} / \mathrm{OH} 4 / 1$

Tablica 5 - Prikaz rezultata DSC-a

Table 5 - DSC results

\begin{tabular}{l|c|c}
\hline Uzorak & $T_{\mathrm{g}(\mathrm{PC})} /{ }^{\circ} \mathrm{C}$ & $T_{\mathrm{g}(\mathrm{PU})} /{ }^{\circ} \mathrm{C}$ \\
\hline Sample & - & $-26,5$ \\
PU ES MDI 2/1 & - & 5,9 \\
PU ES MDI 4/1 & 140,1 & - \\
PC 100 & & \\
PU ES MDI 2/1 : & - & $-20,0$ \\
PU/PC 70/30 & - & $-13,1$ \\
PU/PC 50/50 & - & $-5,2$ \\
PU/PC 30/70 & & \\
PU ES MDI 4/1 : & 118,9 & 13,9 \\
PU/PC 70/30 & 121,3 & 14,9 \\
PU/PC 50/50 & 124,7 & 16,4 \\
PU/PC 30/70 & & \\
\hline
\end{tabular}

\subsubsection{Analiza $D M A$ mješavina $P U / P C$}

Krivulje modula gubitka u ovisnosti o temperaturi za elastomere PU s udjelom NCO/OH od 2/1 i 4/1 prikazane su na slici 12 . Vidljivo je da se $T_{\mathrm{g}}$ meke poliesterske faze pomiče na višu temperaturu dodatkom većeg udjela diizocijanata zbog njezine manje pokretljivosti dodatkom tvrde uretanske faze.

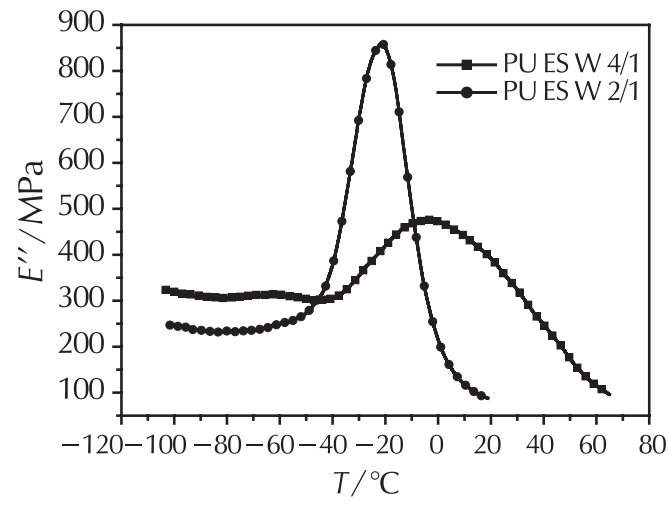

Slika 12 - Modul gubitka u ovisnosti o temperaturi za elastomere PU uz udjel NCO/OH 2/1 i 4/1

Fig. 12 - Loss modulus ( $\left.E^{\prime \prime}\right)$ for PU elastomers with $\mathrm{NCO} / \mathrm{OH}$ $2 / 1$ and $4 / 1$

Na krivuljama modula gubitka u ovisnosti o temperaturi za mješavine PU/PC s manjim (slika 13a)) i većim (slika 13b)) udjelom diizocijanata dobiveno je $T_{\mathrm{g}} \mathrm{PU}$-a meke faze na višoj temperaturi u odnosu na čisti elastomer PU, dok se staklište $\mathrm{PC}$-a pomiče na niže temperature $\mathrm{u}$ odnosu na čisti PC zbog djelomične mješljivosti PU-a i PC-a, tablica 6. Povećanjem udjela diizocijanata i PC-a (slika 13b)) $T_{\mathrm{g}} \mathrm{PU}-\mathrm{a}$ i PC-a dobiveno je na višoj odnosno nižoj vrijednosti temperature $\mathrm{u}$ odnosu na elastomer PU i PC i udjele diizocijanata i PC-a, što ukazuje na poboljšanu mješlji-
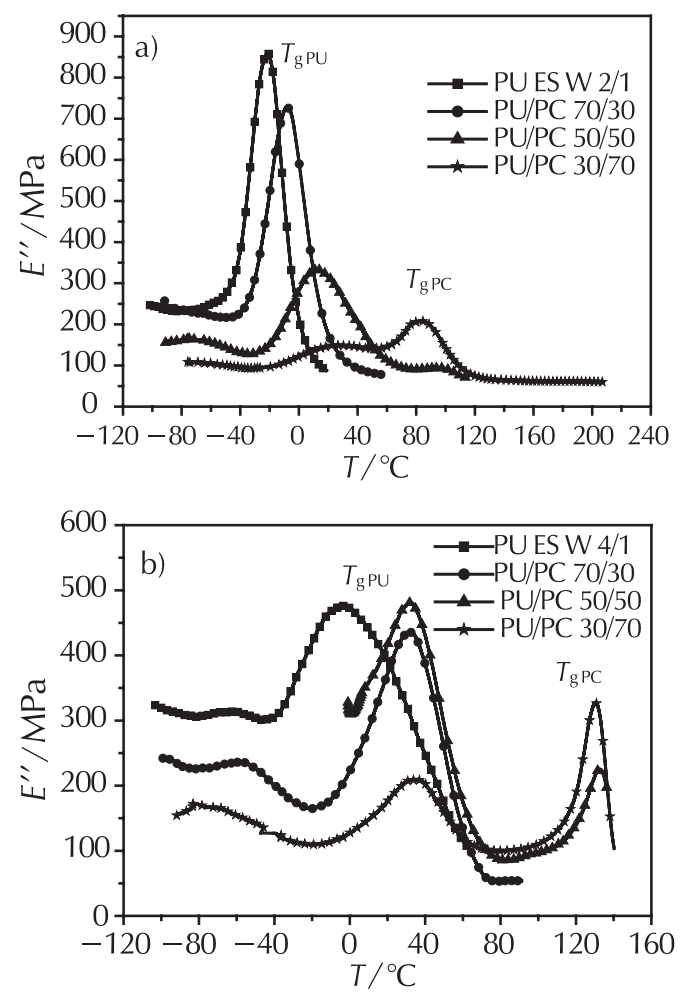

Slika 13 - Modul gubitka $\left(E^{\prime \prime}\right)$ u ovisnosti o temperaturi za mješavine PU/PC u NCO/OH 2/1 (a) i NCO/OH 4/1 (b)

Fig. 13 - Loss modulus ( $\left.E^{\prime \prime}\right)$ for PU/PC blends with a) $\mathrm{NCO} / \mathrm{OH}$ $2 / 1$, and b) $\mathrm{NCO} / \mathrm{OH} 4 / 1$ as a function of temperature 
vost. Iz prethodno prodiskutiranih rezultata za mješavine PU/PC na osnovi aromatskog diizocijanata može se zaključiti da je mješljivost mješavina PU/PC s cikloalifatskim diizocijanatom bolja od mješljivosti mješavina PU/PC na osnovi aromatskog diizocijanata.

Krivulje modula pohrane ili krutosti u ovisnosti o temperaturi za mješavine PU/PC s manjim udjelom diizocijanata prikazane su na slici 14a) i većim udjelom diizocijanata na slici 14b). Iz krivulja su očitane vrijednosti modula krutosti na temperaturi od $25{ }^{\circ} \mathrm{C}$ odnosno temperaturi primjene čije vrijednosti su unesene u tablicu 6. Vidljiv je pomak krivulja na više temperature povećanjem udjela PC-a. Povećanjem udjela diizocijanata i udjela PC-a krivulje se dodatno pomiču na više temperature u odnosu na mješavine PU/PC s manjim udjelom diizocijanata uslijed povećanja krutosti tih mješavina.
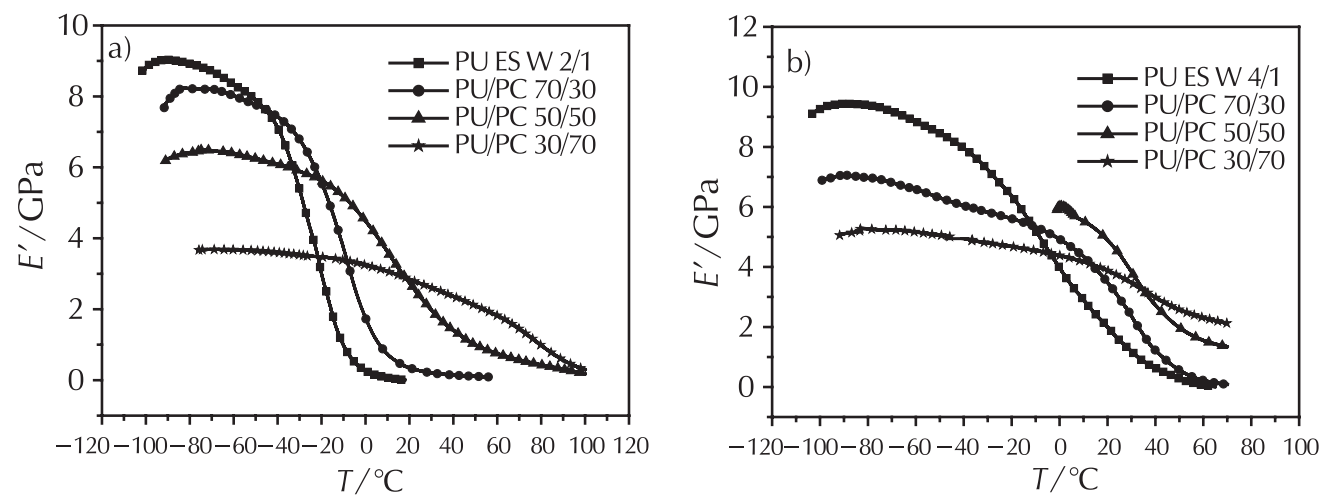

Slika 14 - Modul pohrane $\left(E^{\prime}\right)$ u ovisnosti o temperaturi za mješavine PU/PC uz a) NCO/OH 2/1 i (b NCO/OH 4/1

Fig. 14 - Storage modulus ( $E^{\prime}$ ) for PU/PC blends with a) $\mathrm{NCO} / \mathrm{OH} 2 / 1$, and (b NCO/OH 4/1 as a function of temperature

Tablica 6 - Prikaz rezultata dobivenih mjerenjem DMA

Table 6 - Results obtained by DMA measurements

\begin{tabular}{|c|c|c|c|c|c|}
\hline $\begin{array}{l}\text { Uzorak } \\
\text { Sample }\end{array}$ & $T_{\mathrm{g}(\mathrm{PC})} /{ }^{\circ} \mathrm{C}$ & $T_{\mathrm{g}(\mathrm{PU})} /{ }^{\circ} \mathrm{C}$ & $I_{\mathrm{E}^{\prime \prime} \mathrm{PC}} / \mathrm{MPa}$ & $I_{\mathrm{E}^{\prime \prime P U}} / \mathrm{MPa}$ & $E_{25^{\circ} \mathrm{C}}^{\prime} / \mathrm{GPa}$ \\
\hline $\begin{array}{l}\text { PU ES W 2/1 } \\
\text { PU ES W 4/1 }\end{array}$ & & $\begin{array}{r}-25,1 \\
-2,7\end{array}$ & & $\begin{array}{l}695,1 \\
446,5\end{array}$ & $\begin{array}{l}0,137 \\
1,976\end{array}$ \\
\hline PC 100 & 154,4 & & 1001,0 & & 5,921 \\
\hline $\begin{array}{l}\mathrm{PU} \text { ES W 2/1 } \\
\mathrm{PU} / \mathrm{PC} 70 / 30 \\
\mathrm{PU} / \mathrm{PC} \text { 50/50 } \\
\mathrm{PU} / \mathrm{PC} 30 / 70\end{array}$ & $\begin{array}{c}- \\
96,0 \\
96,6\end{array}$ & $\begin{array}{r}-8,6 \\
11,8 \\
27,7\end{array}$ & $\begin{array}{r}- \\
93,8 \\
308,1\end{array}$ & $\begin{array}{l}714,9 \\
331,7 \\
218,1\end{array}$ & $\begin{array}{l}0,267 \\
2,306 \\
4,582\end{array}$ \\
\hline $\begin{array}{l}\mathrm{PU} \text { ES W 4/1 } \\
\mathrm{PU} / \mathrm{PC} 70 / 30 \\
\mathrm{PU} / \mathrm{PC} 50 / 50 \\
\mathrm{PU} / \mathrm{PC} 30 / 70\end{array}$ & $\begin{array}{c}- \\
131,9 \\
129,7\end{array}$ & $\begin{array}{l}31,3 \\
31,3 \\
33,9\end{array}$ & $\begin{array}{c}- \\
218,6 \\
318,3\end{array}$ & $\begin{array}{l}433,5 \\
478,3 \\
208,9\end{array}$ & $\begin{array}{l}2,891 \\
4,379 \\
3,679\end{array}$ \\
\hline
\end{tabular}

\subsubsection{Mehanička svojstva}

$\mathrm{Na}$ slici 15 prikazane su usporedne krivulje naprezanje-istezanje mješavina PU/PC s manjim udjelom diizocijanata (PU ES W 2/1, slika 15a)) i većim udjelom diizocijanata (PU ES W 4/1, slika 15b)). Rezultati mjerenja dani su u tablici 7. Prekidna čvrstoća kao i prekidno istezanje rastu s povećanjem PC-a kao i udjela diizocijanata u PU-u.
Promjene su više izražene u sustavu s većim udjelom diizocijanata (slika 15b)) kao posljedica bolje mješljivosti u odnosu na mješavine s manjim udjelom diizocijanata, kao i zbog amorfne strukture diizocijanata i PC-a. Dobiveni rezultati pokazuju da mješavine PU-a i PC-a s cikloalifatskim diizocijanatom imaju bolja mehanička svojstva u odnosu na mješavine s aromatskim diizocijanatom, tablica 7 . 

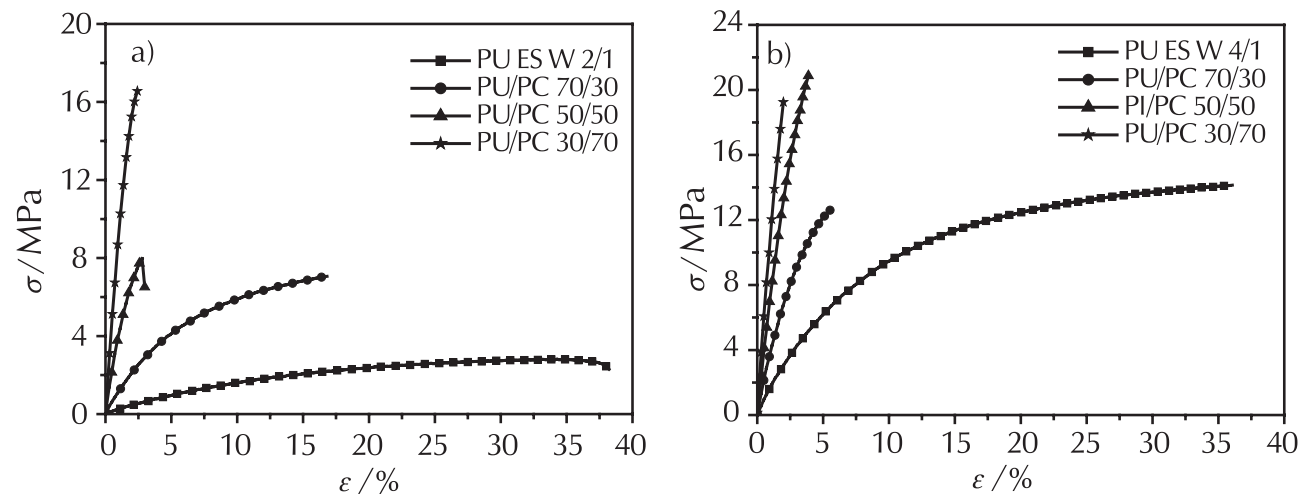

Slika 15 - Krivulje naprezanja-istezanja za mješavine PU/PC a) NCO/OH 2/1 i b) NCO/OH 4/1

Fig. 15 - Stress-strain curves for PU / PC blends a) $\mathrm{NCO} / \mathrm{OH} 2 / 1$, and b) $\mathrm{NCO} / \mathrm{OH} 4 / 1$

Tablica 7 - Prikaz rezultata mehaničkih svojstava

Table 7 - Results of mechanical properties

\begin{tabular}{l|r|r}
\hline $\begin{array}{l}\text { Uzorak } \\
\text { Sample }\end{array}$ & $\sigma / \mathrm{N} \mathrm{mm}^{-2}$ & $\varepsilon / \%$ \\
\hline PUES MDI 2/1 & 2,66 & 230,76 \\
PUES MDI 4/1 & 7,98 & 226,02 \\
PC 100 & 28,30 & 2,00 \\
PU ES MDI 2/1 : & & \\
PU/PC 70/30 & 4,65 & 64,36 \\
PU/PC 50/50 & 14,92 & 9,81 \\
PU/PC 30/70 & 19,03 & 2,90 \\
PU ES MDI 4/1 : & & \\
PU/PC 70/30 & 15,43 & 215,26 \\
PU/PC 50/50 & 16,02 & 6,96 \\
PU/PC 30/70 & 28,60 & 5,22 \\
\hline
\end{tabular}

\section{Zaključci}

- Poliuretanski elastomeri na osnovi aromatskog diizocijanata (MDI) pokazuju kristalnu strukturu u odnosu na poliuretane s cikloalifatskim tipom diizocijanata $\left(\mathrm{H}_{12} \mathrm{MDI}\right)$, koji ima amorfnu strukturu.

- Povećanje udjela diizocijanata kao i polikarbonata dovodi do pomicanja staklišta meke esterske faze na više temperature, odnosno polikarbonata na niže temperature, što ukazuje na djelomičnu mješljivost poliuretana i polikarbonata.

- Kod elastomera PU s većim udjelom diizocijanata (tvrde faze) $T_{\mathrm{g}}$ je pomaknuto na višu temperaturu uslijed smanjenja pokretljivosti meke faze.

- Bolja mješljivost postignuta je kod mješavina PU/PC s cikloalifatskim tipom diizocijanata zbog njegove amorfne strukture.

- Kod mješavina s aromatskim (MDI) tipom diizocijanata uz veći udjel polikarbonata javlja se novi relaksacijski maksimum na temperaturi od $80{ }^{\circ} \mathrm{C}$ kao posljedica interakcija na međupovršini PU-PC.

- Mehanička svojstva poboljšana su u odnosu na čisti PU i PC, prekidna čvrstoća povećava se porastom udjela PC-a i udjela diizocijanata, dok se prekidno istezanje smanjuje.
- Mješavine s cikloalifatskim diizocijanatom pokazuju bolja mehanička svojstva u odnosu na mješavine s aromatskim tipom diizocijanata.

$$
\begin{aligned}
& \text { Popis kratica i simbola } \\
& \text { List of abbreviations and symbols } \\
& \text { PU - poliuretan } \\
& \text { - polyurethane } \\
& \text { PC - polikarbonat } \\
& \text { - polycarbonate } \\
& \text { MDI - 4,4'-difenilmetan-diizocijanat } \\
& \text { - 4,4'-diphenylmethane diisocyanate } \\
& \mathrm{H}_{12} \mathrm{MDI} \text { - 4,4'-dicikloheksilmetan-diizocijanat } \\
& \text { - dicyclohexylmethane diisocyanate } \\
& \text { PUES - poliuretan elastomer } \\
& \text { - polyurethane elastomer } \\
& \text { PCL - polikaprolakton } \\
& \text { - polycaprolactone } \\
& \text { DSC - diferencijalna pretražna kalorimetrija } \\
& \text { - differential scanning calorimetry } \\
& T_{\mathrm{g}} \quad \text { - temperatura staklastog prijelaza } \\
& \text { - glass transition temperature } \\
& T_{\mathrm{m}} \quad \text { - temperatura taljenja } \\
& \text { - melting temperature } \\
& \chi_{\mathrm{c}} \quad \text { - stupanj kristalnosti } \\
& \text { - degree of crystallinity } \\
& T_{\mathrm{m} 1,2} \quad \text { - temperature taljenja nisko uređenih i visoko uređenih }
\end{aligned}
$$


1. H. W. Engels, H. G. Pirkl, R. Albers, R. W. Albach, J. Krause, A. Hoffmann, Polyurethanes: Versatile materials and sustainable problem solvers for today's challenges, Angew. Chemie-Int. 52 (2013) 9422-9441, doi: https://doi.org/10.1002/ anie. 201302766

2. X. Wang, X. Luo, X. Wang, Study on blends of thermoplastic polyurethane and aliphatic polyester: Morphology, rheology, and properties as moisture vapor permeable films, Polym. Test. 24 (2005) 18-24, doi: https://doi.org/10.1016/j. polymertesting.2004.08.003.

3. Y. Di, M. Kang, Y. Zhao, S. Yan, X. Wang, Morphology and mechanical properties of blends of thermoplastic polyurethane and polyolefins, J. Appl. Polym. Sci. 99 (2006) 875-883, doi: https://doi.org/10.1002/app.22809.

4. W. Chen, K. C. Frish, S. Wong, The effect of soft segments on the morphology of polyurethane elastomers, u: K. C. Frisch and D. Klempner (ur.), Advances in Urethane Science and Technology. Vol. 11, Technomic Publishing Co., Inc., Lancaster, Pennsylvania, USA, 1992, str. 110-136.

5. D. Klempner, K. C.Frish, C. L.Wang, Structure -property relationships and morphology of isocyanurate-containing urethane elastomers, u K. C. Frisch and D. Klempner (ur.), Advances in Urethane Science and Technology. Vol. 9, Technomic Publishing Co., Inc., Lancaster, Pennsylvania, USA, 1984, str.102-130.

6. D. Dieterich, H. Hespe, Polyurethane Handbook, G. Oertel, Ch. 2. Hanser, Munich, 1985.

7. J. A. Kornfield, H. W. Spiess, H. Nefzger, H. Hayen, C. D. Eisenbach, Deuteron NMR measurements of order and mobility in the hard segments of a model polyurethane, Macromolecules 24 (1991) 4787-4795, doi: https://doi.org/10.1021/ ma00017a009.

8. T. S. Ellis, Phase bahavior of blends of polyesters and polycarbonates, Polymer 39 (1998) 4741-4749, doi: https://doi. org/10.1016/S0032-3861(98)00009-3.
9. M. Edge, N. S. Allen, J. H. He, M. Derham, Thermal and photooxidative stabilisation behaviour of 4-naphthyl esters of 2-hydroxybenzophenone and 3,5-di-tert-butylphenol in polyolefin films, Polym. Degrad Stab. 44 (1994) 249-255, doi: https://doi.org/10.1016/0141-3910(94)90169-4.

10. P. Sivaraman, N. R. Manoj, S. Barman, L. Chandrasekhar, V. S. Mishra, A. B. Samui, B. C. Chakraborty, Thermoplastic copolyether ester elastomer toughened polycarbonate blends 2. Thermal and rheological studies, Polymer Testing $\mathbf{2 3}$ (2004) 645-649, doi: https://doi.org/10.1016/j.polymertesting.2004.01.012.

11. K. J. Lee, J. M. Kum, J. M. Oh, u: Proceedings of the 1998 $56^{\text {th }}$ Annual Technica Conference, ANTEC Part 2 (of 3); Apr. 26-30 1998., Atlanta. GA, USA.

12. C.-C. Chang, K.-S. Chen, T. L. Yu, Y.-S. Chen, C.-L. Tsai, Y.-H. Tseng, Phase Segregation of Polyester Based-Polyurethanes, Polymer Journal 31 (1999) 1205-1210, doi: https://doi. org/10.1295/polymj.31.1205.

13. T. R. Hesketh, W. C. Van Bogart, L. Cooper, Differential scanning calorimetry analysis of morphological changes in segmented elastomers, Polym. Eng. Sci. 20 (1980) 190-197, doi: https://doi.org/10.1002/pen.760200304.

14. P. S. Archondouli, N. K. Kalfoglou, Compatibilization and properties of PBT/PU polymeric alloys, Polymer 42 (2001) 3489-3502, doi: https://doi.org/10.1016/S00323861(00)00758-8.

15. L. Fambri, A. Penati, J. Kolarik, Modification of polycarbonate with miscible polyurethane elastomers, Polymer 38 (1997) 835, doi: https://doi.org/10.1016/S0032-3861(96)00562-9.

16. T. O. Ahn, S. Jung, J. Lee, H. M. Jeong, Influence of interchange reactions on the miscibility of polyesterurethanes/ polycarbonate binary blends, J. Appl. Polym. Sci. 64 (1997) 2363, doi: https://doi.org/10.1002/(SICI)1097-4628(19970 620)64:12<2363::AID-APP11>3.0.CO;2-2.

\title{
SUMMARY
}

\section{Effect of Type and Content of Diizocyanate on the Thermal and Mechanical Properties of Polyurethane/Polycarbonate Blends

\author{
Emi Govorčin Bajsić and Ana Peršić
}

\begin{abstract}
The miscibility of polyurethane/polycarbonate, PU/PC, blends prepared by mixing of PU elastomers based on polyester polyol as a soft segment and different type and content $(\mathrm{NCO} / \mathrm{OH}=2 / 1$ and 4/1) of hard segments (aromatic (MDI) and cycloaliphatic ( $\mathrm{H}_{12} \mathrm{MDI}$ ) diisocyanate) with PC was investigated. The correlation between the composition of the blends, different type and content of PU diisocyanate, thermal and rheological properties important for the application and the mechanical properties was obtained. The PU/PC blends of PU-elastomers and PC were prepared via melt mixing in a Brabender mixer. Differential scanning calorimetry (DSC) indicated that PU elastomers based on aromatic type of diisocyanate (MDI) had crystalline structure, while the PU elastomers based on cycloaliphatic type of diisocyanate $\left(\mathrm{H}_{12} \mathrm{MDI}\right)$ were of amorphous structure.

The results obtained by dynamic mechanical analysis (DMA) indicated partial miscibility of PU/PC blends. The PU elastomers made from $\mathrm{H}_{12} \mathrm{MDI}$ type of diisocyanate and with higher hard segment content had better miscibility with PC than the PU elastomers made from MDI type of diisocyanate.
\end{abstract}

\section{Keywords}

Polyurethane (PU), polycarbonate (PC), blends, aromatic diisocyanate (MDI), cycloaliphatic diisocyanate $\left(\mathrm{H}_{12} \mathrm{MDI}\right)$

University of Zagreb

Faculty of Chemical Engineering and Technology

Marulićev trg 19, 10000 Zagreb, Croatia
Original scientific paper

Received May 29, 2017

Accepted August 5, 2017 